\title{
Quem tem medo da ilusão biográfica? Indivíduo, tempo e histórias de vida
}

\author{
Maria da Glória de Oliveira*
}

\section{RESUMO}

As críticas dirigidas à biografia, desde a denúncia do "ídolo do individual" de uma recém-fundada ciência sociológica, bem como a desqualificação do seu potencial cognitivo sob o argumento da "ilusão biográfica", sempre tiveram por efeito perpetuar tanto uma noção esvaziada e empobrecida de narrativa, quanto da dimensão temporal constitutiva da identidade de um indivíduo. As reflexóes que proponho neste artigo desenvolvem-se em dois momentos. No primeiro, faço um retorno ao conhecido argumento de desqualificação da credibilidade do biográfico que, em última instância, consistiu na atribuição do estatuto ilusório e fictício às construçóes identitárias, implícitas nas histórias de vida. Em seguida, aponto para uma problematização dessas interdiçóes, com base nas perspectivas abertas pela noção de identidade narrativa formulada por Paul Ricoeur, cujo ganho crucial estaria em confrontar o indivíduo com a experiência do tempo.

Palavras-chave: biografia; História; narrativa; ilusão biográfica; temporalidade.

\section{ABSTRACT}

Since the "idol of the individual" denunciation by a newly founded sociological science, as well as the disqualification of its cognitive potential under the "biographical illusion", the critique of biography has always had the effect of perpetuating both an emptied and impoverished notion of narrative, and the temporal dimension constituting the individual identity. The reflections I propose in this article unfold in two moments. First, I return to the well-known argument of disqualification of the credibility of the biographical, which ultimately consisted in attributing an illusory and fictitious status to the identitary constructions implicit in the life histories. Then, I point to a problematization of such interdictions based on the perspectives opened by the notion of narrative identity formulated by Paul Ricoeur, whose crucial gain would be in confronting the individual with the experience of time.

Keywords: Biography; History; Narrative; Biographical Illusion; Temporality.

DOI - http://dx.doi.org/10.1590/2237-101X01803509

Artigo recebido em 7 de fevereiro de 2017 e aprovado para publicação em 19 de abril de 2017.

* Professora do Departamento de História e Relaçóes Internacionais da Universidade Federal Rural do Rio de Janeiro. Seropédica - RJ, Brasil. Bolsista de produtividade em pesquisa/CNPq. E-mail: mgloriaprof@ gmail.com. 


\section{RESUMEN}

Las críticas a la biografía, desde la denuncia del "ídolo del individual” de una recién-fundada ciencia sociológica, así bien que la descalificación de su potencial cognitivo bajo el argumento de la "ilusión biográfica", siempre han resultado en la perpetuación de una noción vaciada y empobrecida de la narrativa, y también de la dimensión temporal constitutiva de la identidad de un individuo. Las reflexiones que propongo en este artículo se desarrollan en dos momentos. En el primer, hago un retorno al conocido argumento de descalificación de la credibilidad del biográfico que, en último análisis, ha consistido en la atribución del estatuto ilusorio y ficticio a las construcciones identitárias, implícitas en las historias de vida. Enseguida, señalo una problematización de estas interdicciones, con base en las perspectivas abiertas por la noción de identidad narrativa formulada por Paul Ricoeur, cuyo beneficio crucial estaría en confrontar el individuo con la experiencia del tiempo.

Palabras clave: biografía; Historia; narrativa; ilusión biográfica; temporalidad.

Agora é preciso começar. Como? Pelo quê? Pouco importa: podemos entrar em um morto da maneira que quisermos.

Jean-Paul Sartre

E, todavia, essa assimilação da vida a uma história não é evidente, é até uma ideia banal que é preciso, primeiramente, submeter a uma dúvida crítica.

Paul Ricoeur ${ }^{2}$

A biografia sempre remeterá ao tema da unidade, coerência e sentido das experiências vividas por um indivíduo. Das vidas dos grandes varóes ilustres, compostas como espelhos de heroicidade e exemplaridade moral, às trajetórias dos sujeitos comuns, desvendadas sob a chave da pluralidade e heterogeneidade dos contextos sociais que as constituem, a questão crucial que se encontra no cerne do enigma biográfico é a da identidade pessoal, isto é, a do sujeito ou o quem da ação. ${ }^{3}$ Tal perspectiva pode ser pertinente para a reflexão acerca da biografia, na

\footnotetext{
${ }^{1}$ SARTRE, Jean-Paul. Prefácio. In: O idiota da família. Gustave Flaubert de 1821 a 1857. Tradução de Julia da Rosa Simóes. 1. ed. Porto Alegre: L\&PM Editores, 2013, p. 7. v. 1.

${ }^{2}$ RICOEUR, Paul. A vida: uma narrativa em busca de narrador. In: . Escritos e conferências I: em torno da psicanálise. São Paulo: Ediçóes Loyola, 2010, p. 197.

${ }^{3}$ Adoto aqui a expressão "identidade pessoal", em seu sentido filosófico, tal como aparece nos argumentos de
} 
medida em que "a permanência no tempo de uma identidade atribuída"4 funciona como postulado possível para a inteligibilidade e a compreensão de um percurso de vida como totalidade singular. Assim, a condição de possibilidade para que uma existência possa ser narrada como história e, por conseguinte, biografada é a de que um conjunto de açôes possa ser atribuído ao mesmo agente ou sujeito no espaço temporal entre o seu nascimento e a sua morte. ${ }^{5}$

Não por acaso, a ambição de narrar vidas, que deu origem ao gênero biográfico, ao mesmo tempo que tornou notório o seu maior dilema, também não deixaria de tornar evidentes os paradoxos do problema da identidade, isto é, a pressuposição de um sujeito constante e idêntico a si mesmo na disparidade dos eventos que compóem a sua existência. Na contramão da ideia de uma identidade pessoal unitária, coerente e invariável no tempo, uma passagem dos Ensaios, de Montaigne, no capítulo dedicado à inconstância das açôes humanas, já assinalava o problema da radical heterogeneidade da experiência: "somos todos feitos de peças separadas, e num arranjo tão disforme e diverso que cada peça, a todo instante, faz seu próprio jogo". ${ }^{6}$ Não foram poucas as objeçōes do autor quanto aos limites e os riscos de se conhecer verdadeiramente um indivíduo pelos aspectos mais superficiais da sua vida, por conta da volubilidade, ausência de continuidade e falta de coerência das suas açóes. ${ }^{7}$

Poderíamos indagar se não residiria precisamente na condição informe e heterogênea da experiência o desafio imposto aos biógrafos de reunir as "peças separadas" para apreender o suposto "caráter" dos biografados, apresentando "sob a mesma luz" as suas açôes que, disparatadas e contraditórias, pouco fazem além de consubstanciar uma existência. Se a "identidade" nem sempre se apresentou como um problema explícito ou central para aqueles que escreveram biografias, não significa que a questão se desvincule de todo da discussão em torno das possibilidades e dos limites para tornar inteligível uma vida através da narrativa.

Entre os historiadores seduzidos pelo gênero e, ao mesmo tempo, ciosos de suas armadilhas, Lucien Febvre advertiria os leitores de que o seu Lutero não era uma "biografia", pois a despeito do seu esforço em "traçar a curva do destino" daquele personagem singular, importava-se sobretudo com "o problema essencial da história", a saber, o das relaçôes entre o indivíduo e a coletividade, entre a iniciativa pessoal e a necessidade social. ${ }^{8}$ Décadas mais tarde, será a vez de Jacques Le Goff reforçar o adágio de que biografar grandes personagens

Ricoeur, por meio de uma alusão direta a Hannah Arendt, na conclusão do terceiro tomo de Tempo e narrativa: "Dizer a identidade de um indivíduo ou de uma comunidade é responder à pergunta: quem fez tal ação? Quem é seu agente, seu autor?”. RICOEUR, Paul. Tempo e narrativa 3. São Paulo: WMF Martins Fontes, 2010, p. 418. Retomarei essas reflexóes na segunda parte deste artigo.

${ }^{4}$ CANDAU, Joël. Memória e identidade. Tradução de Maria Letícia Ferreira. São Paulo: Contexto, 2012, p. 70.

${ }^{5}$ ARENDT, Hannah. A condição humana. 11. ed. Rio de Janeiro: Forense Universitária, 2013, p. 230-231.

${ }^{6}$ MONTAIGNE, Os ensaios: uma seleção. Tradução de Rosa Freire d'Aguiar. São Paulo: Companhia das Letras, 2010, p. 210.

${ }^{7}$ Para um comentário em torno do tema da subjetividade e experiência da heterogeneidade em Montaigne, ver: LIMA, Luiz Costa. Limites da voz: Montaigne, Schlegel. Rio de Janeiro: Rocco, 1993, p. 29-37.

${ }^{8}$ FEBVRE, Lucien. Lutero. Tradução de Dorothée de Bruchard. São Paulo: Três Estrelas, 2012 [1928], p. 11. 
não era tarefa fácil para historiadores. $\mathrm{Na}$ introdução de São Luís, anuncia que a obra não tem por objeto "a cristandade do século XIII", mas "trata de um homem e não fala de seu tempo a não ser quando isso permita esclarecê-lo". ' Com a investigação biográfica, menos do que se ater a uma "falsa e pretensa oposição entre o indivíduo e a sociedade", Le Goff deparava-se com uma rede complexa de relaçóes, "feita de acasos, de hesitaçôes, de escolhas" que marcavam, em suma, os modos como o rei francês "construiu a si próprio e a sua época, tanto quanto foi construído por ela". ${ }^{10}$

Afinal, "o que se pode saber de um homem?" A questão desponta como chave no prefácio de uma volumosa e inacabada obra, na qual Jean-Paul Sartre nos oferece como resposta o estudo sobre a vida de Flaubert. ${ }^{11} \mathrm{O}$ que merece destaque específico é que, para o filósofo, a tarefa de desvendar a figura do criador do romance moderno demandaria a busca de um "método adequado", capaz de ultrapassar a tarefa de "totalizar" dados e informaçóes disponíveis, pois, em suas palavras, "nada prova, a princípio, que essa totalização seja possível e que a verdade de uma pessoa não seja plural". ${ }^{12}$

Ora, frente a tais desafios, uma resposta usual consistiu em considerar que nenhuma história de vida é pensável sem o recurso da mediação narrativa que estaria na base da própria circunscrição do gênero. ${ }^{13}$ Ademais, a noção moderna de biografia reforçou essa solução, posto que se constituiu na confluência entre um sentido próprio (de relato de uma vida) e um metonímico (os acontecimentos de uma vida). Dito de outro modo, para a biografia, uma só palavra designa, ao mesmo tempo, a operaçáo e o artefato textual que dela resulta. ${ }^{14}$ Assim,

\footnotetext{
${ }^{9}$ LE GOFF, Jacques. São Luís. 3. ed. Tradução de Marcos de Castro. Rio de Janeiro: Record, 2002 [1996], p. 19.

${ }^{10}$ Ibidem, p. 23.

${ }^{11}$ SARTRE, Jean-Paul, Prefácio, op. cit., p. 7. A menção apressada a Sartre feita aqui, sem dúvida, não faz jus à discussão sobre o método biográfico em uma obra como $O$ idiota da família e a sua instrumentalização no contexto mas amplo de suas reflexôes sobre "engajamento" e "dessacralizaçáo" da literatura. Cf. JEFFERSON, Ann. Sartre and biography: existencial acts and the desacralization of literature. In: Biography and the question of literature in France. Nova York: Oxford University Press, 2007, p. 283-305. Por conta das pretensóes limitadas deste artigo, também me abstenho de analisar a ideia de indivíduo como "universal singular", formulada pelo filósofo neste prefácio, ou ainda da abordagem mais específica da noção de "projeto original" que se constituiu em objeto do debate aberto por BOURDIEU, Pierre. As regras da arte: gênese e estrutura do campo literário. Tradução de Maria Lúcia Machado. São Paulo: Companhia das Letras, 1996, p. 202-237.

${ }^{12}$ SARTRE, Jean-Paul, Prefácio, op. cit., p. 7.

${ }^{13}$ A despeito dos seus usos recentes designarem um espectro variado de gêneros como cartas, diários, memórias, documentos pessoais e autobiografias, utilizo aqui a expressão "histórias de vida" no sentido mais estrito, remetendo à própria etimologia da palavra "biografia" (combinação do bios e do graphein dos gregos). Para uma discussão oportuna sobre a amplitude e imprecisão da noção de "Life writing", ver HAAN, Binne de. The eclipse of biography in Life writing. In: RENDERS, Hans; HAAN, Binne de (ed.). Theoretical discussions of biography. Leiden/Boston: Brill, 2014, p. 177-194.

${ }^{14}$ Ibidem, p. 11-13. Importa assinalar que tal conformaçáo semântica confere à palavra biografia a dualidade e a amplitude similares à do moderno conceito de história, como narração e conjunto de fatos que acontecem no tempo.
} 
esta imbricação assinala a centralidade da configuração narrativa, porquanto uma vida não adquire sua verdadeira e definitiva "realidade" senão por meio de e através do seu relato que, em suma, é o que faz "surgir o inteligível do acidental, o universal do singular, o necessário ou o verossímil do episódico". ${ }^{15}$

Ao contrário de se apresentar como um argumento banal, a configuração das vidas individuais em histórias está longe de ser absolutamente evidente. E, no entanto, foi justamente o pressuposto de que a existência do indivíduo pode ser organizada e narrada como um conjunto coerente de acontecimentos que esteve sob a mira da denúncia do caráter "ilusório" e "fictício" do material biográfico. Desde a crítica ao "ídolo do individual" de uma recém-fundada ciência sociológica, ${ }^{16}$ bem como em sua reprise, décadas mais tarde, com a desqualificação radical da pertinência cognitiva do gênero sob o estigma da "ilusão biográfica", até a tentativa recente de polemização filosófica da narratividade, seja como princípio organizador do sentido de uma vida, seja como condição da conduta ética, ${ }^{17}$ os ataques dirigidos ao biográfico sempre tiveram por efeito perpetuar tanto uma noção esvaziada e empobrecida da narrativa quanto da dimensão temporal constitutiva da identidade de um indivíduo.

As reflexóes que proponho a seguir desenvolvem-se em dois momentos principais: no primeiro, faço um breve retorno ao conhecido argumento de desqualificaçáo da credibilidade da biografia que, em última instância, consistiu na atribuição do estatuto ilusório e fictício às construçôes identitárias individuais, implícitas nas histórias de vida. Em seguida, aponto para uma problematização das interdiçôes dirigidas ao biográfico com base nas perspectivas abertas pela noçáo de identidade narrativa, formulada por Paul Ricoeur, cujo ganho crucial, a meu ver, estaria em confrontar o indivíduo com a experiência do tempo. Ao contrário do que a amplitude do tema possa sugerir, cabe ressaltar os limites deste ensaio quanto à pretensão de abarcar o espectro de implicaçôes teóricas relacionadas com o problema do indivíduo e da identidade pessoal, notadamente em seus recentes e profícuos debates nas áreas da filosofia e das ciências sociais. ${ }^{18}$

\footnotetext{
${ }^{15}$ RICOEUR, Paul. Tempo e narrativa 1. Tradução de Claudia Berliner. São Paulo: WMF Martins Fontes, 2010, p. 74.

${ }^{16}$ SIMIAND, François. Méthode historique et science sociale. Annales. Économies, Sociétés, Civilisations. ano 15, n. 1, p. 83-119, 1960 [1903].

${ }^{17}$ STRAWSON, Galen. Against narrativity. Ratio (new series), v. XVII, p. 428-452, dez. 2004.

${ }^{18}$ Uma contextualização concisa do problema no campo da tradição filosófica encontra-se em TAYLOR, Charles. As fontes do self: a construção da identidade moderna. 4. ed. São Paulo: Edições Loyola, 2013, p. 209-257. Para uma análise comparativa do problema da temporalidade, sujeito e narrativa na filosofia contemporânea francesa, ver MULDOON, Mark. Tricks of time: Bergson, Merleau-Ponty and Ricoeur in search of time, self and meaning. Pittsburgh: Duquesne University Press, 2006. Sobre o debate da identidade pessoal e da unicidade do sujeito no campo da teoria sociológica, ver LAHIRE, Bernard. O homem plural. Lisboa: Instituto Piaget, 2001, p. 21-58.
} 


\section{A ilusão de uma ilusão?}

E, enfim, por que não eliminar completamente, pelo menos da história científica, estes trabalhos consagrados a biografias puras e simples do insignificante primo de um grande homem, remetendo-os à história anedótica e ao romance histórico, em que deverão se juntar aos Affaires du collier e todas as Familias de Napoleão, considerando que não temos trabalhos suficientes sobre a indústria e a agricultura no tempo de Turgot e ignoramos quase completamente a vida econômica da França sob a Revolução e o Império? ${ }^{19}$

Não obstante o relativo prestígio conquistado pelo gênero no âmbito da história social, entre aqueles que ousaram fazer usos da biografia como instrumento e método de pesquisa, poucos se sentiram impelidos a explorar teoricamente a questáo da ação dos indivíduos nos contextos históricos com tenacidade semelhante à dos sociólogos e antropólogos, frente ao problema análogo das relações entre indivíduo e sociedade. ${ }^{20}$ Para os historiadores profissionais, empenhados na afirmação do estatuto científico da disciplina, uma via de solução predominante estaria na postura de recusa sumária e adesão radical à denúncia sociológica do "ídolo do individual" e, mais tarde, da "ilusão biográfica". ${ }^{21}$

${ }^{19}$ SIMIAND, François, Méthode historique et science sociale, op. cit., p. 118. Na tradução da passagem citada, mantive a referência do artigo "Méthode historique et science social" em sua versão francesa original, de 1903, cotejando-a com a edição recente em português SIMIAND, François. Método histórico e ciência social. Bauru: Edusc, 2003. p. 113.

${ }^{20}$ Sobre essa questão cardeal para a sociologia, é impossível não remeter ao ensaio clássico de Norbert Elias, A sociedade dos indivíduos, escrito em 1939. No atual panorama das ciências sociais, a tônica do debate deslocou-se para uma variedade de teorizaçóes sobre o sujeito. Para um balanço conciso sobre o problema da agency ver, por exemplo, ORTNER, Sherry B. Subjetividade e crítica cultural. Horizontes Antropológicos, Porto Alegre, ano 13, n. 28, p. 375-405, jul./dez. 2007. Uma discussão sobre as relaçóes entre o problema da agency e da linguagem encontra-se em SHAW, David Gary (Ed.). Agency after postmodernism. History and Theory. v. 40, n. 4, dez. 2001.

${ }^{21}$ Desde o final dos anos 1970, o debate acerca das escalas de análise propôs fazer dos nomes próprios e dos itinerários de vida de indivíduos ou grupos de indivíduos a baliza para uma renovação da história social, com ênfase no estudo das complexas redes de relaçóes coletivas e da multiplicidade dos espaços e tempos nos quais se inscrevem, a partir de uma densa documentação serial. Nesse sentido, tornaram-se paradigmáticas as proposiçóes de Giovanni Levi em torno da biografia como estratégia heurística ideal para investigar o caráter intersticial das ações e coações dos atores históricos frente às práticas e normas sociais. REVEL, Jacques. A biografia como problema historiográfico. In: História e historiografia: exercícios críticos. Curitiba: Editora UFPR, 2010, p. 235-248. 
O célebre artigo de Pierre Bourdieu, publicado em dossiê de mesmo título, nas Actes de la Recherche en Sciences Sociales, em junho de 1986, continha não somente os ingredientes de um epitáfio melancólico do gênero, mas, de modo incisivo, firmava a postura de radical suspeição epistêmica frente aos argumentos de defesa de qualquer valor cognitivo das histórias de vida no campo das ciências sociais. ${ }^{22}$ Aquela que se tornaria uma das mais influentes denúncias das armadilhas epistemológicas do biográfico figurava, curiosamente, como o único texto teórico no meio de um conjunto de 12 estudos que, sob tematizaçóes diversas, faziam usos e mençôes explícitos a testemunhos, histórias de vida, relatos autobiográficos ou entrevistas orais, seja como objetos de discussóes de cunho metodológico ou como fonte de pesquisa. ${ }^{23}$

Alguns anos mais tarde, Nathalie Heinich indagava-se acerca da opção editorial do sociólogo francês em não alocar de modo mais explícito o seu "Lillusion biographique" como texto de apresentação daquela edição da revista. ${ }^{24}$ No comentário, Heinich conjetura se isso não revelaria certo escrúpulo do seu editor em relação aos autores, o que serviria, sem dúvida, para "atenuar o efeito de autocontradição" que a desqualificação do biográfico faria incidir sobre o próprio objeto de estudo das contribuiçóes selecionadas para aquele número.

A observação adquire mais sentido se lembrarmos que Heinich participara como coautora com Michael Pollak do artigo "Le témoignage", que abria o referido dossiê. No texto, afirmava-se, de imediato, o estatuto privilegiado da abordagem biográfica como instrumento de investigação, sobretudo por seu potencial heurístico acerca da construção das identidades sob o impacto das experiências-limite traumáticas, justificando o estudo comparativo dos diferentes tipos de testemunhos de sobreviventes do campo de Auschwitz-Birkenau. ${ }^{25} \mathrm{Um}$ dos argumentos centrais do trabalho assinalava precisamente que, nos

${ }^{22} \mathrm{O}$ uso da metodologia de histórias de vida remontava à década de 1920, com os estudos da chamada Escola de Chicago e, após certo declínio, retornou com força no final dos anos de 1970, sobretudo na França, com a abordagem biográfica proposta pelo sociólogo do trabalho Daniel Bertaux, no artigo "L'approche biographique: sa validité méthodologique, ses potentialités", publicado em 1980. Essa retomada coincidia com a redescoberta da oral history por pesquisadores americanos, ingleses ou outros europeus. PENEFF, Jean. Les grandes tendances de l'usage des biographies dans la sociologie française. Politix, v. 7, n. 27, p. 25-31, 1994.

${ }^{23}$ Entre os autores dos trabalhos incluídos no dossiê, destacam-se Michael Pollak, Nathalie Heinich, Aloïs Hahn, Pierre Pénisson, Bernard Zarca, Patrice Pinell e Howard S. Becker. Para um quadro resumido com os temas e problemas centrais de cada um dos treze artigos, ver COSTA, Patrícia Claudia da. Ilusão biográfica: a polêmica sobre o valor das histórias de vida na sociologia de Pierre Bourdieu. Revista Linhas. Florianópolis, v. 16, n. 32, p. 51-71, set./dez. 2015.

${ }^{24} \mathrm{HEINICH}$, Nathalie. Pour en finir avec l' "illusion biographique". L'Homme, n. 195-196, p. 421-430, 2010. Disponível em: <https://www.cairn.info/revue-l-homme-2010-3-page-421.htm\#re3no3>. Acesso em: dez. 2016. Em 1986, a Actes de la Recherche en Sciences Sociales estava em seu décimo primeiro ano de existência, tendo sido editada por Bourdieu desde a sua criação em 1975 até 2002, ano de sua morte, por meio de cadernos temáticos trimestrais que incluíam, além de artigos, notas de pesquisa, relatórios de campo em sociologia e disciplinas afins e resenhas. Ver WACQUANT, Loïq. O legado sociológico de Pierre Bourdieu: duas dimensóes e uma nota pessoal. Revista de Sociologia Política, Curitiba, v. 19, p. 95-110, nov. 2002.

${ }^{25}$ POLLAK, Michael; HEINICH Nathalie. Le témoignage. Actes de la Recherche en Sciences Sociales. L'illusion biographique, v. 62-63, p. 3-4, jun. 1986. 
casos extremos de ameaça à integridade física e moral dos indivíduos, o próprio esforço de manutenção das identidades marcaria um ato de resistência à "experiência concentracionária”. Por conta disso, os testemunhos das vítimas não deveriam ser considerados como meros relatos de memória, reduzidos à sua função informativa factual, mas como instrumentos de reconstrução das identidades sob o impacto do trauma, o que colocava em questão as "fronteiras do dizível", ou seja, as próprias condições de enunciação e elaboração possíveis dessa experiência pelos sobreviventes.

A pesquisa com os relatos de sobreviventes, concluíam Pollak e Heinich, revelava o quanto era difícil a manutenção da "continuidade e coerência", tanto por um indivíduo como por um grupo, posto que isso resultaria "de um trabalho permanente de gestão da identidade" que consistiria em "interpretar, ordenar e reprimir (temporária ou definitivamente) toda experiência vivida, de modo a torná-la coerente em relação às experiências passadas", o que significava, em suma, "integrar o presente ao passado". Ora, mesmo não sendo tematizada de modo direto, na asserção dos autores acerca das estratégias de gestão da identidade e da memória por meio da elaboração da experiência traumática, não estaria implicada uma atividade essencialmente narrativa?

Desde que consideremos a centralidade crescente dos debates em torno da história oral e da história do tempo presente, no contexto de publicação do artigo, em meados dos anos 1980, a defesa dos usos do material biográfico apresentava-se sob os argumentos do valor documental do testemunho do vivido para a compreensáo dos fenômenos sociais. Estaria no apelo ao caráter estritamente testemunhal a via de legitimação e de defesa da biografia frente às alardeadas suspeiçóes quanto aos seus limites cognitivos? E, neste caso, ainda poderíamos indagar, a história de vida de um indivíduo teria valor de documento e estatuto de testemunho do quê?

\title{
Experiência do tempo e identidade narrativa
}

\begin{abstract}
[...] acaso náo consideramos mais legíveis as vidas humanas quando interpretadas em função das histórias que as pessoas contam sobre elas? E essas histórias de vida, por sua vez, não se tornam mais inteligíveis quando lhes são aplicados modelos narrativos - enredos extraídos da história propriamente dita ou da ficção (drama ou romance)? ${ }^{26}$
\end{abstract}

\footnotetext{
${ }^{26}$ RICOEUR, Paul. O si-mesmo como outro. Tradução de Ivone C. Benedetti. São Paulo: WMF Martins Fontes, 2014, p. 112.
} 
Na conclusão de $O$ pequeno $x$, Sabina Loriga argumenta que a dissipação das suspeitas em relação à dimensão individual da história e o retorno da biografia no campo historiográfico contemporâneo, ao abrirem a perspectiva de abordagem dos atores no entrecruzamento de experiências sociais plurais e diversas, também trouxeram consigo o mal-estar da fragmentação e a "sensação de vertigem" diante do trabalho interminável de contextualização histórica, tornando inalcançável qualquer esforço de totalização. ${ }^{27}$

Como sintoma e efeito desse quadro paradoxal, Loriga identifica duas utopias que sempre inspiraram os usos do biográfico entre os historiadores e profissionais das ciências humanas em geral. A primeira delas seria a da representatividade da experiência do indivíduo, investida do estatuto de "ponte" e "espelho" para a compreensão de categorias sociais mais abrangentes. Por essa via, a pesquisa biográfica justificar-se-ia tấo somente por seu potencial de generalização, em detrimento da preocupação com as especificidades dos destinos individuais ou das idiossincrasias pessoais. Não é necessário lembrar o quanto a adesão a esse pressuposto reverbera, em grande parte, as premissas contidas na denúncia sociológica do "ídolo do individual" e da "ilusáo biográfica", contribuindo para a escrita de uma história sem nomes ou sujeitos e, portanto, desprovida de impressóes digitais. A outra utopia biográfica, embora afastada da busca de "espelhos" individuais que reflitam as coletividades históricas, reforçaria a pretensão naturalista de apreender uma época, dessa vez, reconstituindo cada um de seus elementos da forma mais exaustiva possível (como, por exemplo, o método prosopográfico), para se chegar a "categorias interpretativas plenamente aderentes à realidade empírica". ${ }^{28}$

Não há dúvida de que as demandas epistêmicas dirigidas ao biográfico, sobre as quais nos adverte Loriga, constituem-se sintomas tangíveis de uma relação que permanece problemática entre biografia e história, a despeito da notória conformação paulatina do gênero aos imperativos de uma historiografia com fundamentos "científicos". Desde que se afastou de suas ambiçôes moralizantes, a escrita biográfica também sofreu os impasses do questionamento oriundo do campo da teoria social acerca dos pressupostos da identidade individual única e invariável. ${ }^{29}$ Como uma espécie de antídoto ao regime modelar das vidas exemplares, o gênero biográfico passou a operar menos com o pressuposto das identidades fixas, talhadas à maneira das estátuas de bronze e, cada vez mais, com uma miríade de traços fragmentados e heterogêneos (os "biografemas" de Barthes), para sublinhar o caráter plural, múltiplo e paradoxal das açóes e itinerários individuais. ${ }^{30}$ Contudo, náo obstante o esforço de se desviar

${ }^{27}$ LORIGA, Sabina. O pequeno x: da biografia à história. Belo Horizonte: Autêntica, 2011, p. 222.

${ }^{28}$ Ibidem, p. 222-224.

${ }^{29}$ LAHIRE, Bernard. O homem plural, op. cit., p. 27.

${ }^{30}$ DOSSE, François. O desafio biográfico: escrever uma vida. São Paulo: Edusp, 2009, p. 406. Sobre a noção de "biografemas", Barthes afirma: "Do mesmo modo, gosto de certos traços biográficos que, na vida de um escritor, me encantam tanto quanto certas fotografias; chamei esses traços de 'biografemas'; a fotografia tem com a História a mesma relação que o biografema tem com a biografia”. BARTHES, Roland. A câmara clara. Tradução de Júlio Castañon Guimarães. Rio de Janeiro: Nova Fronteira, 1984, p. 34. 
das armadilhas ilusórias das histórias de vida em favor da apreensão dos ritmos não lineares e das imbricaçôes contextuais múltiplas que perpassam uma existência individual, a escrita de biografias nunca deixou de se confrontar com o problema da experiência do tempo.

Quando introduziu o conceito de identidade narrativa como corolário de sua tese acerca do círculo hermenêutico da temporalidade e da narratividade, Paul Ricoeur também intentava responder à interrogaçáo formulada na conclusão de Tempo e narrativa 3, em torno da existência de alguma estrutura de experiência capaz de integrar as duas grandes modalidades de narrativa, a histórica e a ficcional. ${ }^{31}$ A hipótese sustentada, então, era de que, embora não se apresentasse como solução definitiva para as aporias da temporalidade, a noção de identidade narrativa mostrava-se fecunda para evidenciar o entrecruzamento entre história e ficção na configuração da experiência de um tempo humano, indivisamente fenomenológico e cosmológico. ${ }^{32}$

É importante ter em vista que a operação narrativa se baseia na construção da intriga, capaz de configurar eventos ou incidentes múltiplos em um todo dotado de coesão e sentido. Daí o argumento ricoeuriano de que o enredo implica uma operaçáo de síntese do heterogêneo, cujo resultado consiste em uma história que sempre é mais do que a enumeraçáo dos acontecimentos em ordem sucessiva..$^{33}$ Ademais, o ponto de origem de qualquer estrutura narrativa está no fato de que alguém agiu em um dado tempo, o que permite a articulação entre enredo e personagem: "narrar é dizer quem fez o quê, por quê...". ${ }^{4}$ Portanto, compreendida, grosso modo, como "a atribuição a um indivíduo ou a uma comunidade de uma identidade específica", a noção de identidade narrativa diz respeito ao agente e autor da ação, introduzindo a indagação acerca do suporte de permanência do nome próprio: "o que justifica que se considere que o sujeito da ação, assim designado por seu nome, é o mesmo ao longo de toda uma vida que se estende do nascimento à morte?"35

O elemento fundamental, neste ponto da reflexão, está na explícita evocação de Ricoeur à teoria da ação de Hannah Arendt, para se apoiar menos no argumento da autora acerca do vínculo entre o agir e a pluralidade da vida política, e mais no sentido de enfatizar a imbricação entre ação e discurso na resposta à pergunta "quem és?". Se, nas páginas iniciais de A condição humana, lê-se que "a ação, na medida em que se empenha em fundar e preservar corpos políticos, cria a condição para a lembrança [remembrance], ou seja, a história", ${ }^{36}$ será em uma passagem posterior da obra que, por força de sua delimitação etimológica, o agir recupera o significado de "tomar iniciativa, iniciar (como indica a palavra grega archein,

\footnotetext{
${ }^{31}$ RICOEUR, Paul, $O$ si mesmo como outro, op. cit., p. 112, nota 1.

${ }^{32}$ RICOEUR, Paul. Tempo e narrativa 3. Tradução de Cláudia Berliner. São Paulo: WMF Martins Fontes, 2010, p. 422.

${ }^{33}$ RICOEUR, Paul, A vida: uma narrativa em busca de narrador, op. cit., p. 198.

${ }^{34}$ RICOEUR, Paul, O si mesmo como outro, op. cit., p. 153.

${ }^{35}$ RICOEUR, Paul, Tempo e narrativa 3, op. cit., p. 418.

${ }^{36}$ ARENDT, Hannah, A condição humana, op. cit., p. 10.
} 
"começar", "conduzir" e, finalmente, "governar"), imprimir movimento a alguma coisa (significado original do termo em latim agere)". ${ }^{37}$

A ação, prossegue Arendt, constitui um initium, sendo da natureza do início que se instaure algo novo em relaçáo àquilo ocorrido antes e, portanto, o fato de o homem, na condição de "alguém que é único" dada por seu nascimento, ser capaz de agir, "significa que se pode esperar dele o inesperado, que ele é capaz de realizar o infinitamente improvável". ${ }^{38}$ A ação em seu sentido de "início" remete, assim, à evidência da natalidade dos sujeitos, enquanto o discurso "corresponde ao fato da distinção" e, por isso, "é a efetivação da condição humana da pluralidade, isto é, do viver como um ser distinto e único entre iguais". A revelação acerca do agente está implicada tanto em suas palavras quanto em seus feitos, na medida em que a ação, "desacompanhada do discurso, perderia não somente o seu caráter revelador, como, e pelo mesmo motivo, o seu sujeito". ${ }^{39}$

Alinhado a esses pontos da argumentação de Arendt, a resposta à pergunta sobre o quem da ação, ou da identidade do sujeito ao qual determinado agir se vincula, para Ricoeur, não pode ser dada senão pela narrativa. Em outras palavras, sem o socorro da mediação narrativa não há como se enfrentar as antinomias com que a tradição filosófica, desde Locke e Hume, circunscreveu a categoria de sujeito, ora enaltecido como idêntico a si mesmo na diversidade de seus estados (o cogito cartesiano), ora relegado ao estatuto de uma "ilusão" substancialista (o anticogito nietzschiano), porquanto reduzido à mera autoconsciência da diversidade de suas cogniçôes, emoçôes e voliçóes. ${ }^{40} \mathrm{O}$ dilema encontraria uma solução na medida em que a identidade pessoal, entendida no sentido do mesmo (idem) como um núcleo idêntico, fixo e não mutável, fosse substituída pela compreensão da identidade como um si-mesmo (ipse). A noção de ipseidade, proposta por Ricoeur, colocaria em evidência, portanto, a dimensão temporal implicada tanto no sujeito quanto na sua ação: "diferentemente da identidade abstrata do mesmo, a identidade narrativa, constitutiva da ipseidade, pode incluir a mudança, a mutabilidade, na coesão de uma vida”. ${ }^{41}$

\footnotetext{
${ }^{37}$ Ibidem, p. 221.

${ }^{38}$ Ibidem, p. 222.

${ }^{39}$ Ibidem, p. 223.

${ }^{40} \mathrm{O}$ conceito filosófico da identidade do self como um problema de autopercepção, ou seja, como ser inseparável da consciência de si mesmo, foi inaugurado por Locke nos termos de um ser dotado de razão e reflexão, "capaz de considerar-se a si mesmo como si mesmo, a mesma coisa pensante em diferentes tempos e lugares" (Locke apud TAYLOR, Charles. As fontes do self: a construção da identidade moderna, op. cit., p. 72-73). Mais tarde, a compreensão do sujeito idêntico a si mesmo, como lócus substancial e permanente, encontraria os seus limites em Hume que, no Tratado sobre a natureza humana (1739-40), define a identidade pessoal como série de percepçôes mentais fugazes, ou seja, desde que nenhum eu mesmo pode ser encontrado para além de um "feixe de diferentes percepçóes", este não seria nada além de uma ficção. MULDOON, Mark. Tricks of time: Bergson, Merleau-Ponty and Ricoeur in search of time, self and meaning. Pittsburgh: Duquesne University Press, 2006, p. 4.
}

${ }^{41}$ RICOEUR, Paul, Tempo e narrativa 3, op. cit., p. 419. 
Constituída no jogo cruzado da história e da ficção na refiguração do tempo, a identidade narrativa, seja ela pensada tanto para o indivíduo ou para uma coletividade, afasta-se da premissa do núcleo identitário estável, sem falhas. Assim como sempre é possível narrar eventos idênticos com enredos distintos, pode-se compor uma biografia a partir de intrigas diferentes ou até opostas, pois "a história de uma vida não cessa de ser refigurada por todas as histórias verídicas ou fictícias que um sujeito conta sobre si mesmo". ${ }^{42}$ Tal como a noção de representância problematizara as relaçôes entre a narrativa historiográfica e a "realidade" do passado, a identidade narrativa, nos termos formulados por Ricoeur, "torna-se assim título de um problema, ao menos tanto quanto de uma solução". ${ }^{43}$

Se no terceiro tomo de Tempo e narrativa as reflexôes convergem para a tese do entrecruzamento entre história e ficção frente às aporias da temporalidade, será no conjunto de estudos reunidos sob o título de $O$ si-mesmo como outro, publicados em 1990, que encontraremos o esforço mais efetivo do filósofo em preencher a lacuna deixada em suspenso, no tocante às articulaçóes da identidade pessoal na dimensáo temporal tanto da existência do sujeito quanto da sua ação. ${ }^{44}$ Para tanto, Ricoeur propõe a retomada da tese narrativista, não mais na perspectiva das suas relações com a configuração do tempo humano, mas de sua contribuição para o problema da constituição do si, através da dialética entre os conceitos de identidade como mesmidade e de identidade como ipseidade, no latim, idem e ipse, respectivamente, que sinalizariam modos distintos de permanência no tempo. ${ }^{45}$

No âmbito do problema da identidade pessoal, a noção de ipseidade, ao contrário da identidade no sentido de idem e de mesmo, coloca em primeiro plano náo o substrato imutável de um pretenso núcleo identitário do sujeito, mas a dinâmica mutável da condiçáo temporal capaz de ser configurada sob a forma narrativa, constituindo-o enquanto tal. Dito de outro modo, a identidade no sentido de mesmidade remete ao caráter do sujeito, ou seja, ao conjunto de disposiçóes e traços duráveis pelos quais se reconhece um indivíduo, à maneira de suas impressóes digitais, enquanto a ipseidade, tal como a entende Ricoeur, implica outra modalidade de permanência no tempo, que não a da suposta constância do caráter, mas a de uma manutençâa e atestaçâo de si que se constitui como uma vontade de identidade mantida a despeito da mudança. ${ }^{46}$

\footnotetext{
42 Idem.

${ }^{43}$ Ibidem, p. 422. Sobre a noçáo de representância como problematização proposta por Ricoeur acerca da nossa capacidade de falar sobre e representar o passado, ver LEAL. Ivanhoé Albuquerque. História e ação na teoria da narratividade de Paul Ricoeur. Rio de Janeiro: Relume Dumará, 2002, p. 88-89.

${ }^{44}$ Já na conclusão de Tempo e narrativa 3, Ricoeur evoca o problema do sujeito da açáo, levantada por Hannah Arendt, em $A$ condição humana, para introduzir o problema da "identidade" no sentido de uma categoria da prática: "dizer a identidade de um indivíduo ou de uma comunidade é responder à pergunta: quem faz tal ação? (...) Responder à pergunta "quem? ”, é contar a história de uma vida." RICOEUR, Paul, Tempo e narrativa 3, op. cit., p. 418.

${ }^{45}$ RICOEUR, Paul, O si mesmo como outro, op. cit., p. 118.

${ }^{46}$ Ibidem, p. 124. A ideia de manutenção de si possui uma conotação necessariamente ética nas reflexões de Ricoeur, na medida em que denota a postura de responsabilidade de um sujeito que presta contas de suas açóes perante outrem.
} 
Menos do que uma chave de solução instantânea, a mediação narrativa aprofunda o problema da identidade do sujeito, trazendo para o primeiro plano todas as suas implicaçôes temporais. Isso porque, no contraste entre os dois usos do conceito de identidade (no sentido de idem e de ipse) — o que está em jogo é a possibilidade de uma vida ser apreendida como totalidade singular e, sobretudo, narrada como uma unidade. ${ }^{47}$

Entre as dificuldades fundamentais a serem enfrentadas pela tese narrativista aplicada às histórias de vida estaria, antes de tudo, a própria "falta de acabamento" narrativo da experiência vivida. Ademais, ao contrário das narrativas ficcionais, as histórias de vida de cada um seriam marcadas pelo entrecruzamento na história de muitos outros e pelo caráter aberto quanto ao seu começo e fim:

(...) nada na vida real tem valor de começo narrativo; (...) meu nascimento e, com mais razão, o ato pelo qual fui concebido, pertencem mais à história dos outros que a mim mesmo. Quanto à minha morte, só será um fim narrado na narrativa daqueles que sobreviverem a mim (...).48

Como, indaga Ricoeur, sustentar a premissa da "unidade narrativa de uma vida", sem considerar nela "um misto instável entre fabulação e vivência"? Neste caso, o que se tornaria imperativo considerar seria "a aplicação da ficção à vida". Dito de outro modo, sem o recurso à ficção e a despeito do caráter provisório e revisável de toda e qualquer configuração de enredo, náo seria possível organizar retrospectivamente os acontecimentos sob o modo de uma "história de vida".

Onde, afinal, se situa a identidade narrativa no espectro das duas modalidades de permanência no tempo, marcadas pela manutenção de si, de um lado, e pela perpetuação do mesmo, de outro? Se a resposta à pergunta já parece dada pelo estatuto atribuído à noçáo como elo de mediação entre ipseidade e mesmidade, a dificuldade que reabrirá o debate, como assinala Ricoeur, é aquela que emerge da dissolução e perda da identidade do sujeito que a ficção literária não deixou de documentar, como em $O$ homem sem qualidades, de Robert Musil, mediante a afirmação desconcertante do personagem principal: "Não sou nada." Neste caso, é interessante notar que a anulaçáo e o eclipse da identidade da personagem acompanham um outro apagamento: o das qualidades propriamente narrativas do romance. ${ }^{49}$

Mas, na perspectiva das duas modalidades de identidade, o que significaria a perda da identidade do sujeito e a concomitante diluição da forma narrativa? Poderíamos tomar a frase do personagem de Musil como sinônimo de despojamento extremo de um eu privado

\footnotetext{
${ }^{47}$ Neste caso, a discussão de Ricoeur está dirigida, de modo mais pontual, aos argumentos de MACINTYRE, Alasdair. After virtue: a study on moral theory. Indiana: University of Notre Dame Press, 1981, acerca da "unidade narrativa de uma vida" como condição para o sujeito da ação conferir um sentido ético à própria existência. RICOEUR, Paul, O si mesmo como outro, op. cit., p. 168-171.

${ }^{48}$ Ibidem, p. 171.

${ }^{49}$ Ibidem, p. 156.
} 
do "socorro da mesmidade"? Por acaso, o "não-sujeito" não continuaria sendo "uma figura do sujeito, mesmo que no modo negativo"? Quem é ainda eu quando o sujeito diz que não é nada? E, por fim, questiona Ricoeur, como manter no plano ético um sujeito que, no plano narrativo, parece ter se apagado? $\mathrm{O}$ encadeamento de tais indagaçóes emerge no fechamento de um dos estudos de $O$ si-mesmo como outro como ponto de inflexão de Ricoeur na direção de um exame mais detido das determinaçôes éticas e implicações morais da ação e da narrativa. ${ }^{50}$

\section{Identidade narrativa contra a ilusão biográfica?}

$\mathrm{O}$ que merece destaque no percurso esboçado até aqui são as contribuiçóes possíveis da noção de identidade narrativa de Ricoeur na problematização da operação biográfica, especialmente quanto à pertinência da atribuição de sentido e inteligibilidade a uma vida narrada como história. Como já sugerido por François Dosse, as reflexôes do filósofo francês sobre o problema da identidade nos desdobramentos de sua tese acerca da circularidade entre tempo e narrativa podem ser uma via para contornar as aporias da narrativa biográfica, que se manifestam no dilema de todo biógrafo entre o suposto caráter coeso e invariável do sujeito biografado e a notória multiplicidade de contradiçôes e incongruências que caracterizam uma existência individual..$^{51}$

Para além do impasse entre uma identidade fundadora do sujeito e a sua radical dissolução sob a denúncia da sua "ficção", Ricoeur propôe uma forma de identidade (como ipseidade) que, longe de pressupor a busca de um substrato imutável e idêntico através do desdobramento linear de uma vida, confronta o indivíduo com o tempo, incluindo as mutaçôes e contingências constitutivas de sua relação com o outro. Em suma, o que está no cerne da noção e, por conseguinte, apresenta-se como perspectiva fecunda para a renovação da legitimidade da tarefa biográfica é a ênfase na temporalidade do sujeito (o quem da ação), cuja identidade não se torna tangível fora das mediaçôes narrativas "que não cessam de se fazer e se desfazer".

Em que medida uma hermenêutica do si, nos moldes propostos pelo filósofo francês, pode fazer frente à desqualificação sumária contida na denúncia da ilusão biográfica pela teoria social bourdieusiana? Por acaso, tal denúncia não reverbera, sob muitos aspectos, as

\footnotetext{
${ }^{50}$ A questão central em torno das relaçôes entre teoria narrativa e ética é formulada nos seguintes termos: "(...) de que maneira o componente narrativo da autocompreensão atrai como complemento as determinaçóes éticas próprias à imputação moral da ação e seu agente?”. Ibidem, p. 175.

${ }^{51}$ DOSSE, François. O desafio biográfico: escrever uma vida, op. cit., p. 341. Para uma defesa das contribuiçôes da noção de identidade narrativa no campo da sociologia, incluindo uma discussão pontual sobre os problemas deixados em aberto pelo conceito de habitus de Bourdieu, ver TRUC, Gérôme. Narrative identity against biographical illusion. Études Ricoeuriennes, v. 2, n. 1, 2011, p. 150-167.
} 
reflexôes melancólicas de um Montaigne sobre a inconstância das açôes humanas e, sobretudo, as asserçôes céticas de um Hume acerca do estatuto fictício do eu e da ilusão da identidade pessoal? E, em última instância, a suspeição radical dirigida ao biográfico e às histórias de vida não mereceria ser problematizada a partir da frágil premissa que a sustenta, ou seja, a de uma suposta e inalcançável identidade do indivíduo no sentido do que permanece idêntico no tempo, um si que seja sempre o mesmo?

Não por acaso, a ideia de atestação e manutenção de si possui um desdobramento necessariamente ético nas reflexóes de Ricoeur, na medida em que denota a postura de responsabilidade de um sujeito que presta contas de suas açóes perante outrem. ${ }^{52}$ Recentemente, a filósofa Judith Butler argumentou que uma nova postura ética talvez consista não apenas em fazer a pergunta "quem és?", mas continuar fazendo-a sem esperar uma resposta completa ou definitiva do outro a quem coloco a questão, de modo a não capturá-lo dentro de moldes identitários fixos, mas mantendo sempre vivo certo "desejo de reconhecimento". ${ }^{33}$ Mas, deixar em aberto a pergunta "quem és", sem esperar a resposta completa e final, não pressupõe que a experiência vivida também possa ser compreendida naquilo que excede o relato que dela possamos elaborar?

Menos do que propor uma via de soluçáo, talvez seja mais oportuno lembrar do "desconcertante problema" a que se refere Hannah Arendt quando pontua um aspecto crucial nas relaçôes entre ação, sujeito e discurso: ninguém é autor ou produtor de sua própria história. ${ }^{54} \mathrm{~A}$ constatação de que, em qualquer totalização de eventos na composição das narrativas, podemos, no máximo, identificar os agentes, sujeitos ou "heróis" que puseram "o processo em movimento", mas nunca podemos designá-los inequivocamente como "autores do resultado final", tornou-se mais evidente com as filosofias modernas da história, ou seja, com a compreensão de que "embora a história deva a sua existência aos homens, obviamente não é, todavia, 'feita' por eles". ${ }^{55} \mathrm{E}$, sem dúvida, talvez nada denote a afirmação da natureza política da história - como narrativa de atos e feitos humanos - do que a pressuposição de um ator "invisível" nos bastidores (a providência, o espírito do mundo, a luta de classes...). A atribuição de uma "mão invisível" que estaria por trás das açôes humanas decorreria, para Arendt, de uma "perplexidade mental", pois a história "real" que vivemos, não possui criador visível ou invisível porque não é inventada (como a história de ficção). $\mathrm{O}$ único "alguém" que a história vivida revela é o seu herói; e ela (a história) é o único meio pelo qual a manifestação originalmente intangível de um "quem" pode se tornar tangível ex post facto por meio da ação e do discurso.

\footnotetext{
${ }^{52}$ RICOEUR, Paul, O si-mesmo como outro, op. cit., p. 177.

${ }^{53}$ BUTLER, Judith. Relatar a si mesmo: crítica da violência ética. Tradução de Rogério Bettoni. Belo Horizonte: Autêntica, 2015, p. 61.

${ }^{54}$ ARENDT, Hannah, op. cit., p. 232.

${ }^{55}$ Ibidem.
} 
À luz da perspectiva lançada pela filósofa alemã e, muito longe de reforçar relaçôes demasiadamente diretas e rudimentares entre experiência vivida e narrativa, as reflexóes de Ricoeur permitem atravessar o lapso aberto entre vida, narrativa e ficção em suas zonas mais críticas, culminando com uma noção de subjetividade cujos pressupostos ultrapassam as aporias da natureza "ilusória" ou substancial da identidade pessoal, para afirmar um modo de ação dos sujeitos no tempo, cujos sentidos se abrem e se refiguram nas operaçóes imbricadas de escrita e de leitura das narrativas.

\section{Referências bibliográficas}

ARENDT, Hannah. A condição humana. 11. ed. Rio de Janeiro: Forense Universitária, 2013. BARTHES, Roland. A câmara clara. Tradução de Júlio Castañon Guimarães. Rio de Janeiro: Nova Fronteira, 1984.

BOURDIEU, Pierre. L'illusion biographique. Actes de la Recherche en Sciences Sociales. Lillusion biographique, v. 62-63, p. 69-72, jun. 1986. Disponível em: <http://www.persee. fr/issue/arss_0335-5322_1986_num_62_1>. Acesso em: dez. 2015.

- As regras da arte: gênese e estrutura do campo literário. Tradução Maria Lúcia Machado. São Paulo: Companhia das Letras, 1996.

BUTLER, Judith. Relatar a si mesmo: crítica da violência ética. Tradução de Rogério Bettoni. Belo Horizonte: Autêntica, 2015.

CANDAU, Joël. Memória e identidade. Traduçáo de Maria Letícia Ferreira. São Paulo: Contexto, 2012.

COSTA, Patrícia Claudia da. Ilusão biográfica: a polêmica sobre o valor das histórias de vida na sociologia de Pierre Bourdieu. Revista Linhas, Florianópolis, v. 16, n. 32, p. 51-71, set.l dez. 2015.

DOSSE, François. O desafio biográfico: escrever uma vida. São Paulo: Edusp, 2009.

ELIAS, Norbert. A sociedade dos individuos. Rio de Janeiro: Zahar, 1994.

FEBVRE, Lucien. Lutero. Tradução de Dorothée de Bruchard. São Paulo: Três Estrelas, 2012. HEINICH, Nathalie. Pour en finir avec l' 'illusion biographique". L'Homme, n. 195-196, p. 421-430, 2010. Disponível em: <https://www.cairn.info/revue-l-homme-2010-3-page421.htm\#re3no3>. Acesso em: dez. 2015.

HUME, David. Tratado da natureza humana. 2. ed. rev. e ampl. Tradução de Déborah Danowski. São Paulo: Editora Unesp, 2009.

JEFFERSON, Ann. Sartre and biography: existencial acts and the desacralization of literature. In: . Biography and the question of literature in France. Nova York: Oxford University Press, 2007, p. 283-305. 
LAHIRE, Bernard. O homem plural. Lisboa: Instituto Piaget, 2001.

LEAL. Ivanhoé Albuquerque. História e ação na teoria da narratividade de Paul Ricoeur. Rio de Janeiro: Relume Dumará, 2002.

LE GOFF, Jacques. São Luís. 3. ed. Tradução de Marcos de Castro. Rio de Janeiro: Record, 2002.

LIMA, Luiz Costa. Limites da voz: Montaigne, Schlegel. Rio de Janeiro: Rocco, 1993.

LORIGA, Sabina. O pequeno $x$ : da biografia à história. Belo Horizonte: Autêntica, 2011.

MACINTYRE, Alasdair. After virtue: a study on moral theory. Indiana: University of Notre Dame Press, 1981.

MONTAIGNE. Os ensaios: uma seleção. Tradução de Rosa Freire d'Aguiar. São Paulo: Companhia das Letras, 2010.

MULDOON, Mark. Tricks of time: Bergson, Merleau-Ponty and Ricoeur in search of time, self and meaning. Pittsburgh: Duquesne University Press, 2006.

ORTNER, Sherry B. Subjetividade e crítica cultural. Horizontes Antropológicos, Porto Alegre, ano 13, n. 28, p. 375-405, jul./dez. 2007.

PENEFF, Jean. Les grandes tendances de l'usage des biographies dans la sociologie française. Politix, v. 7, n. 27, p. 25-31, 1994.

POLLAK, Michael; HEINICH Nathalie. Le témoignage. Actes de la Recherche en Sciences Sociales. L'illusion biographique, v. 62-63, p. 3-29, jun. 1986.

RICOEUR, Paul. Tempo e narrativa 2. A configuração do tempo na narrativa de ficção. Tradução de Márcia Valéria Martinez de Aguiar. São Paulo: WMF Martins Fontes, 2010.

. Tempo e narrativa 3. O tempo narrado. Traduçáo de Cláudia Berliner. São Paulo: WMF Martins Fontes, 2010.

. Escritos e conferências I: em torno da psicanálise. São Paulo: Edições Loyola, 2010.

. O si-mesmo como outro. Tradução de Ivone C. Benedetti. São Paulo: WMF Martins

Fontes, 2014.

RENDERS, Hans; HAAN, Binne (Ed.). Theoretical discussions of biography. Leiden/Boston: Brill, 2014.

REVEL, Jacques. A biografia como problema historiográfico. História e historiografia: exercícios críticos. Curitiba: Ed. UFPR, 2010, p. 235-248.

SHAW, David Gary (Ed.). Agency after Postmodernism. Theme Issue. History and Theory, v. 40, n. 4, dez. 2001.

SIMIAND, François. Méthode historique et science sociale. Annales. Économies, Sociétés, Civilisations. ano 15, n. 1, p. 83-119, 1960 [1903]. . Método histórico e ciência social. Bauru: Edusc, 2003. 
STRAWSON, Galen. Against narrativity. Ratio (new series), v. XVII, p. 428-452, dez. 2004. TAYLOR, Charles. As fontes do self: a construção da identidade moderna. 4. ed. São Paulo: Ediçóes Loyola, 2013.

TRUC, Gérôme. Narrative Identity against Biographical Illusion. Études Ricoeuriennes, v. 2, n. 1, p. 150-167, 2011.

WACQUANT, Loïq. O legado sociológico de Pierre Bourdieu: duas dimensôes e uma nota pessoal. Revista de Sociologia Política, Curitiba, v. 19, p. 95-110, nov. 2002. 